\title{
Estimating Preferential Flow in Karstic Aquifers Using Statistical Mixed Models
}

\author{
by Angel A. Anaya ${ }^{1}$, Ingrid Padilla ${ }^{2}$, Raul Macchiavelli ${ }^{3}$, Dorothy J. Vesper ${ }^{4}$, John D. Meeker ${ }^{5}$, and
}

Akram N. Alshawabkeh ${ }^{6}$

\begin{abstract}
Karst aquifers are highly productive groundwater systems often associated with conduit flow. These systems can be highly vulnerable to contamination, resulting in a high potential for contaminant exposure to humans and ecosystems. This work develops statistical models to spatially characterize flow and transport patterns in karstified limestone and determines the effect of aquifer flow rates on these patterns. A laboratory-scale Geo-HydroBed model is used to simulate flow and transport processes in a karstic limestone unit. The model consists of stainless steel tanks containing a karstified limestone block collected from a karst aquifer formation in northern Puerto Rico. Experimental work involves making a series of flow and tracer injections, while monitoring hydraulic and tracer response spatially and temporally. Statistical mixed models (SMMs) are applied to hydraulic data to determine likely pathways of preferential flow in the limestone units. The models indicate a highly heterogeneous system with dominant, flowdependent preferential flow regions. Results indicate that regions of preferential flow tend to expand at higher groundwater flow rates, suggesting a greater volume of the system being flushed by flowing water at higher rates. Spatial and temporal distribution of tracer concentrations indicates the presence of conduit-like and diffuse flow transport in the system, supporting the notion of both combined transport mechanisms in the limestone unit. The temporal response of tracer concentrations at different locations in the model coincide with, and confirms the preferential flow distribution generated with the SMMs used in the study.
\end{abstract}

\section{Introduction}

Karst groundwater systems develop in soluble rocks, such as limestone and dolomites, and are characterized by well-developed conduit porosity and high permeability zones. These characteristics make karst aquifers highly productive and important fresh water resources for human consumption and ecological integrity of streams, wetlands, and coastal zones. Karst areas occupy large areas of the planet's ice-free continental areas $(\sim 20 \%)$ and provide roughly 20 to $25 \%$ of the global population water needs (Ford and Williams 2007). The same characteristics that

${ }^{1}$ Department of Civil Engineering and Surveying, University of Puerto Rico, Mayagüez, PR 00681; angel.anaya@upr.edu

${ }^{2}$ Corresponding author: Department of Civil Engineering and Surveying, University of Puerto Rico, Mayagüez, PR 00681; (787) 832-4040; fax: 787-265-3390; ingrid.padilla@upr.edu

${ }^{3}$ Department of Crops and Agro-Environmental Sciences, University of Puerto Rico, Mayagüez, PR 00681; raul.macciavelli @upr.edu

${ }^{4}$ Department of Geology \& Geography, West Virginia University, Morgantown, WV 26506; dorothy.vesper@mail.wvu.edu

${ }^{5}$ Department of Environmental Health Sciences, University of Michigan, Ann Arbor, MI 48109; meekerj@umich.edu

${ }^{6}$ Department of Civil and Environmental Engineering, Northeastern University, Boston, MA 02115; aalsha@coe.neu.edu

Received July 2012, accepted May 2013.

(c) 2013, National Ground Water Association.

doi: $10.1111 /$ gwat.12084 make karst aquifers highly productive, make them highly vulnerable to contamination (Green et al. 2006; Göppert and Goldscheider 2008), and impart an enormous capacity to convey contaminants from sources to potential exposure zones. As a result, karst aquifers serve as an important route for contaminant's exposure to humans and wildlife.

Karst terrains are characterized by well-developed conduit porosity, but flow in these systems may occur through fractures, conduits, and the rock matrix (Martin and Dean 2001; White 2002). Differences in flow capacity through these regions give rise to a spectrum of flow modes, which range from diffuse to conduit flow. It has been widely accepted that flow in karst aquifers is mostly concentrated in conduits, while most water is stored in the rock matrix (Martin and Dean 2001). This is certainly the case for many telogenetic aquifers, which have been developed in rocks that are exposed after porosity reduction of burial diagenesis (Vacher and Mylroie 2002). These aquifers are characterized by dense, low-porosity rocks with a well-developed conduit network (Vacher and Mylroie 2002; Bailly-Comte et al. 2010) and are mostly associated with continental karst (Vacher and Mylroie 2002), such as those found in southern France, Germany, and Kentucky, USA. In less diagenetically altered carbonate rocks that have significantly greater primary porosity and permeability, aquifers may have significant flow components through the rock 
matrix. As a result, both conduit and matrix flow could contribute to flow in these carbonate aquifers. This is the particular case of karst aquifers that occur in eogenetic systems, which have developed in carbonate rocks that have not undergone deep burial and are under active meteoritic diagenesis (Vacher and Mylroie 2002). Eogenetic karst aquifers are widely distributed near the warm, low-latitude environments and include (1) karst islands, such as Bahamas, Bermuda, Barbados, and Guam; and (2) karst formations in larger islands, such as Puerto Rico and Jamaica, and continental settings, and such as those found in the Floridan, Yucatan, and Edwards aquifers (Mylroie 2001; Vacher and Mylroie 2002; Screaton et al. 2004; Mylroie and Mylroie 2007).

Transport of contaminants in karst groundwater occurs in complex pathways and is influenced by the porosity character of the media, which controls and affects hydraulic gradients, velocities, storage capacity, and advective-dispersive, sorptive, and reactive processes (Field and Pinsky 2000). Conduit-flow-dominated systems tend to convey solutes rapidly through the system without much attenuation. For instance, tracer tests conducted in highly karstified system in the Gallusquelle catchment in southwest Germany (Geyer et al. 2007) and the Austro-German Alps (Göppert and Goldscheider 2008) exhibit rapid transport through conduits with temporal concentration distributions that are highly dominated by advective transport. Diffuse-flow systems, on the other hand, can cause significant solute retardation and slow movement. These two mechanisms represent end members of a wide spectrum of conditions found in karst areas, and often a combination of conduit- and diffuseflow mechanisms is encountered (Martin and Dean 2001; White 2002; Screaton et al. 2004; Bailly-Comte et al. 2010), where both flow mechanisms can control the fate and transport of contaminants. Combined conduit- and diffuse-flow transport mechanisms occur over a wide range of hydrogeological systems and flow conditions (Mylroie 2001; Vacher and Mylroie 2002; White 2002; Screaton et al. 2004; Mylroie and Mylroie 2007), but are closely associated with karst systems with high matrix permeability, such as those found in eogenetic carbonate aquifers of northern Puerto Rico (Renken et al. 2002; White 2002) and southern Florida (USA). In such systems, conduits can concentrate water and contaminants from direct sources and/or diffuse flow and convey them rapidly to discharge points at springs and wells. They can also convey contaminants to "trapping" diffuse flow zones of low permeability, slow flow, and high contaminant storage capacity, thereby resulting in long-term storage and source of contamination. Historical assessment of groundwater contamination in the northern karst aquifers of Puerto Rico has indeed shown significant contaminant distribution beyond the demarked sources of contamination and a strong capacity of the karst groundwater system to store and slowly release contamination (Padilla et al. 2011). Tracer tests conducted in the Biscayne aquifer of southern Florida have shown rapid breakthrough of solutes moving through touching-vug flow zones, and high degree of solute tailing associated with slower advection and chemical diffusion in the rock matrix (Renken et al. 2008; Shapiro et al. 2008).

The interaction and relative flow rates of water and solutes in conduits and the rock matrix in karst aquifers lead to complex flow-dependent transport behavior (Loop and White 2001; Screaton et al. 2004; Bailly-Comte et al. 2010). During times of rapid groundwater recharge, increased pressure heads in conduits can force water and solutes into adjacent pores and fissures (White 1999; Bailly-Comte et al. 2010). As groundwater flow and pressure heads decrease after recharge events, contaminants stored in fractures and rock matrix may migrate through diffuse transport into the conduits, resulting in slow release and long-term source of contaminants. The bidirectional exchange of water and solutes between conduits and matrix porosity is particularly important for eogenetic karst aquifers having high matrix permeability, and has been shown to occur in the aquifers of northcentral Florida, USA (Screaton et al. 2004; Bailly-Comte et al. 2010), as well as in several laboratory-scale karst models (Florea and Wicks 2001; Li 2004; Faulker 2008).

Assessment of potential exposure risk requires knowledge of the fate and transport processes controlling the temporal and spatial paths of contaminants in the system. It is particularly important to know characteristics associated with conduit and preferential flow regions in dual porosity systems, such as those found in many karst environments. These characteristics impart great control on the flow, transport and, storage dynamics of the system (Dreiss 1989; Einsiedl 2005).

Much of the fate and transport work conducted in karst systems has focused on simplified conceptual models (Wolfe et al. 1997; Loop and White 2001; Vesper et al. 2001; Wolfe and Haugh 2001; Li 2004). Owing to their high complexity, only a few transport models have been developed for karst aquifers (Clemens et al. 1996; Field 1997; Teutsch and Sauter 1998; Lapcevic et al. 1999; Scanlon et al. 2003; Sauter et al. 2006; Kovacs and Sauter 2007; Reimann and Hill 2009). Many of these models are limited by very simplifying assumptions or by lack of information of subsurface characteristics. There is, therefore, a need to develop technologies that can provide geometric and subsurface characteristics for modeling purposes (Field and Nash 1997; Birk et al. 2006), particularly for karst aquifers in which flow and transport is influenced by conduit and matrix porosity.

Statistical methods are useful for estimating hydrogeologic and hydraulic characteristics when it is not possible to obtain sufficient spatial data (Hill 2008). Different statistical models have been applied in karst regions to describe distribution and geometries of caves (Curl 1999), estimate secondary porosity (Mace et al. 2005), and simulate conduit enlargement (Jaquet et al. 2004). A need, however, exists to develop statistical models that can be applied to locate and characterize regions of preferential flow in karst systems. Because regions of preferential flow in these systems are influenced by anisotropic pore or conduit connectivity, the models must rely 
on the development of spatial autocorrelation functions that incorporate directional components. Statistical mixed models (SMMs) have been used to integrate distance functions and anisotropy in stream networks (Peterson and Ver Hoef 2010) and geostatistical models (Schabenberger and Gotway 2005). SMMs, however, have not been applied to define autocorrelation structures that relate to flow patterns in karst groundwater systems.

The main objectives of this work are to (1) develop statistical treatments that can spatially characterize flow and transport patterns in karstified limestone having high matrix permeability and conduit porosity; and (2) determine the effect of aquifer flow rates on these patterns. SMMs are applied to hydraulic and tracer data to characterize the location, geometry, and transport patterns of preferential flow regions in a laboratory-scale physical model developed to simulate flow and transport processes in karstic environments. Initial hydraulic characterization indicates a highly heterogeneous system with strong preferential flow components that vary with flow regimes.

\section{Materials and Methods}

Saturated flow and transport experiments were conducted in a 2D Geo-HydroBed (GHB) physical model packed with a limestone block. The design of the GHB model allows conducting experiments that can be used to characterize preferential flow regions (presented in this work) and hydraulic properties of the media. The GHB model can also simulate fate and transport processes in karst systems that could not be done at the field scale because of limitations on data resolution (i.e., not enough data in space and time) and the inability to conduct transport experiments in the field using hazardous contaminants. In this regards, the GHB model can be used to study fundamental processes affecting the fate and transport of aqueous and nonaqueous phase contaminants.
Once understood at the laboratory-scale level, these processes can be assessed at the field scale using available data of limited resolution. Other laboratory-scale "karst" flow models have been developed and used to simulate the exchange of water and pollutants between a conduit and the adjacent matrix porosity and provide data that can be used in calibrating numerical models (Florea and Wicks 2001; Li 2004; Faulker 2008). These models, however, have simulated karst systems as a collection of conduit networks built along ceramic plates (Florea and Wicks 2001) or as a single built conduit surrounded by unconsolidated porous medium represented by glass beads ( $\mathrm{Li}$ 2004; Faulker 2008). Unlike the research presented in this work, none of the previously documented laboratory-scale models used actual limestone medium characterized by real conduits and matrix porosity.

Experiments involve injecting water and tracers into the GHB model and monitoring the pressure, flow rates, and concentration response spatially and temporally. SMMs are applied to develop the best spatial autocorrelation structure (SACS) that represents the response of the system. This structure is used to estimate preferential flow and transport regions under different flow regimes.

\section{Geo-HydroBed Physical Model}

The GHB consists of a stainless steel tank (20-cm deep, 20-cm wide, and 102-cm long), packed with a limestone block (Figure 1) having dimensions of $15 \mathrm{~cm} \times 15 \mathrm{~cm} \times 76 \mathrm{~cm}$. The limestone block (Figure 1a) was collected from the outcrop area of the Aymamon Limestone, which is the most exposed limestone formation in the shallow karst aquifer of northern Puerto Rico. Groundwater flow in this formation is controlled by matrix and secondary porosity (Giusti 1978). The GHB tank is divided into three chambers (Figure $1 \mathrm{~b}$ and 1c): an upstream mixing chamber (5-cm long) having magnetic stirrers to induce well-mixed conditions; the (a)

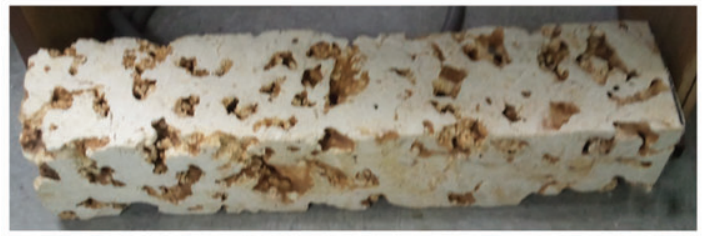

(c)

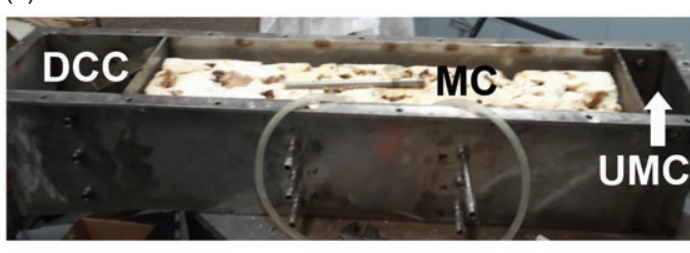

(b)

(d)
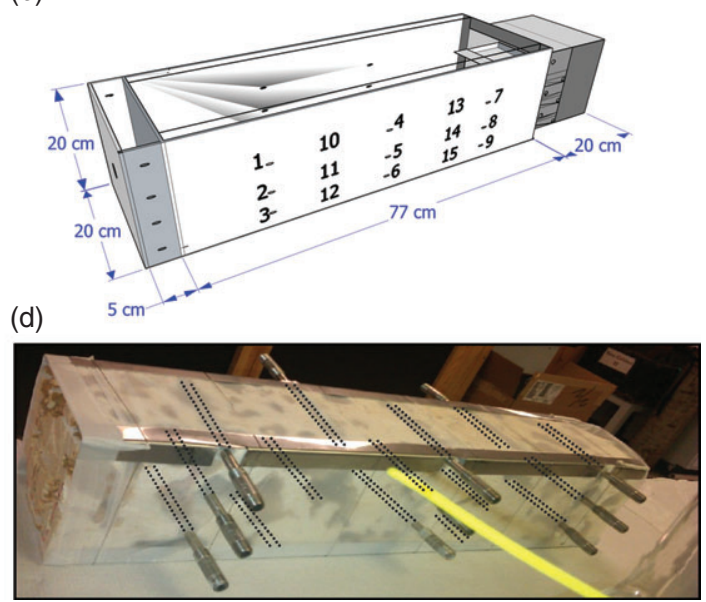

Figure 1. The GHB model: (a) limestone block from Aymamon Formation, (b) tank schematic, (c) limestone block inside tank, and (d) nylon mesh and samplers surrounding the limestone block. Port numbers are shown in the lateral face of the tank schematic (b). UMC and DCC in (c) refer to the upstream mixing chamber and the discharge-capture chamber, respectively. Dotted lines in (d) illustrate the general location of samplers in the limestone. 
main chamber $(77 \mathrm{~cm})$ holding the limestone block; and a discharge-capture chamber $(20 \mathrm{~cm})$ at the downstream face of the limestone. The later chamber is designed to collect dissolved and nonaqueous phase liquids (such as trichloroethylene, phthalates, and tracers) exiting the limestone. A stainless steel porous plate (Mott Corporation, Farmington, Connecticut) with an average pore size of $100 \mu \mathrm{m}$ separates the upstream and limestone chambers. The upstream mixing chamber has ports to monitor water pressure and solute concentration at the upstream boundary of the model.

The limestone block is wrapped with a nylon mesh cloth (average bubbling pressure of $30 \mathrm{mb}$, Soil Measurements, AZ; Figure 1d) and placed into the stainless steel tank. The bottom, top, and lateral faces of the limestone block are sealed with a layer of bentonite clay $(\sim 2.5 \mathrm{~cm}$ thick) to establish no-flow boundaries and prevent preferential flow along the boundary contacts of the GHB. Crushed limestone (average size $0.3 \mathrm{~cm}$ ) is placed between the porous plate and the upstream limestone face to diffuse flow evenly across the inlet boundary. Fifteen sampling/injection ports are installed in the limestone to serve as water injection points and monitor temporal and spatial water pressures and solute concentrations (Figure 1d). The samplers consist of stainless steel tubes $(1 \mathrm{~cm}$ in diameter, $20-\mathrm{cm}$ long with an $11-\mathrm{cm}$ perforated zone. They are inserted through horizontal boreholes drilled $11 \mathrm{~cm}$ into the limestone. Samplers are distributed in three layers located 0, 5, and $10 \mathrm{~cm}$ from the bottom of the limestone block. Each layer contains five ports located at $13,25,38,51$, and $64 \mathrm{~cm}$ from the upstream limestone face. Every sampler is coupled to a digital pressure sensor (PC256GW, Honeywell), and a sampling valve. Pressure sensors are connected to a data acquisition system controlled by a computer and a data logger (model CR 5000, Campbell Science, Logan, Utah).

The GHB tank is connected upstream to two feeder tanks that supply water to the model (Figure 2). The feeder tanks are connected to a $4 \mathrm{~m}^{3}$ stainless steel storage tank that receives water from a groundwater well located at the University of Puerto Rico, Mayagüez. Measured water quality parameters $\left(\mathrm{pH}, \mathrm{Ca}^{+2}, \mathrm{Mg}^{+2}\right.$,
$\mathrm{Na}^{+}$, total dissolved solids, $\mathrm{SO}_{4}{ }^{-2}, \mathrm{NO}_{2}{ }^{-}, \mathrm{NO}_{3}{ }^{-}, \mathrm{PO}_{4}{ }^{-3}$, $\mathrm{Cl}^{-}, \mathrm{F}^{-}$) in the well water show general geochemical characteristics similar to those found in the northern coast of Puerto Rico (Giusti 1978; Zack et al. 1987). The storage tank is equipped with a primary disinfection system comprised of ultraviolet light lamps $\left(75 \mathrm{~W} / \mathrm{m}^{2}\right.$ output, emitting at wavelengths of $320 \mathrm{~nm}$ ). The outlet of the GHB tank discharges into a waste storage tank.

\section{Experimental Method}

Flow and transport experiments are conducted in the GHB model to determine the effect of different flow regimes on the preferential flow patterns in the limestone model. The experiments involve establishing steady-state background flow under confined conditions, in which the limestone unit was completely saturated and subjected to constant pressurized conditions at the inflow and outflow boundaries of the GHB. Experiments are conducted under low $(2.5 \mathrm{~mL} / \mathrm{min})$, medium $(375 \mathrm{~mL} / \mathrm{min})$, and high $(750 \mathrm{~mL} / \mathrm{min})$ background flow conditions. The range of water flux (flow per unit area) used in the experiments $\left(1.79 \times 10^{-4}-5.38 \times 10^{-2} \mathrm{~cm} / \mathrm{s}\right)$ includes one value within the average maximum and minimum estimates $\left(4.23 \times 10^{-6}-2.94 \times 10^{-3} \mathrm{~cm} / \mathrm{s}\right)$ reported by Giusti (1978) for the Aymamon Limestone and two values beyond these estimates.

Flow experiments are conducted by injecting a pulse of water into the steady background flow through a lateral sampling/injection port while monitoring pressure response in all ports. Water is injected under a constant head condition for $10 \mathrm{~min}$, followed by a recovery period of $20 \mathrm{~min}$. Temporal measurements indicate that these periods are sufficient to attain constant pressures in the system. The injection/recovery process is repeated in all sampling/injection ports, and the changes in water pressures recorded and related to hydraulic response.

Transport experiments are conducted to assess the transport behavior of dissolved tracers along the different flow regions in the GHB. They involve injecting a $20 \mathrm{mM} \mathrm{CaCl} 2$ solution into the head waters of the GHB model for $3 \mathrm{~h}$, followed by a flushing period of $6 \mathrm{~h}$. Samples are taken from the sampling ports at different times throughout the experiment and analyzed for

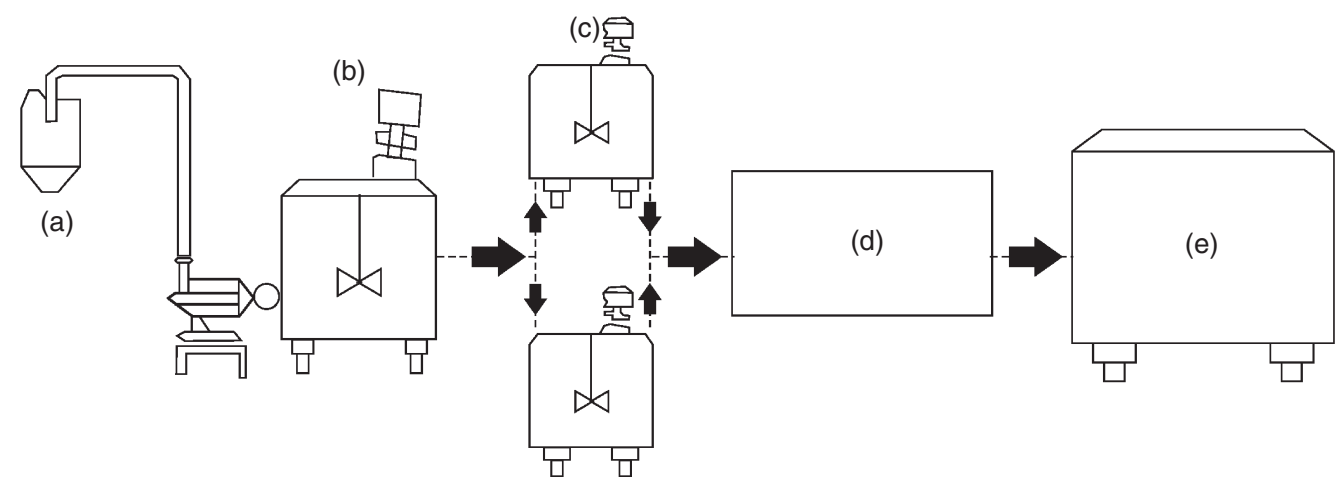

Figure 2. Schematic diagram of the physical model integrating the (a) groundwater well, (b) disinfection tank, (c) solute tanks, (d) GHB, and (e) waste storage tank. 


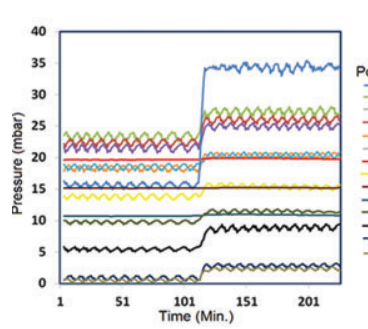

(a)

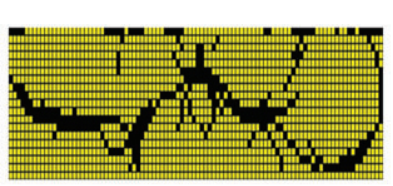

(g)
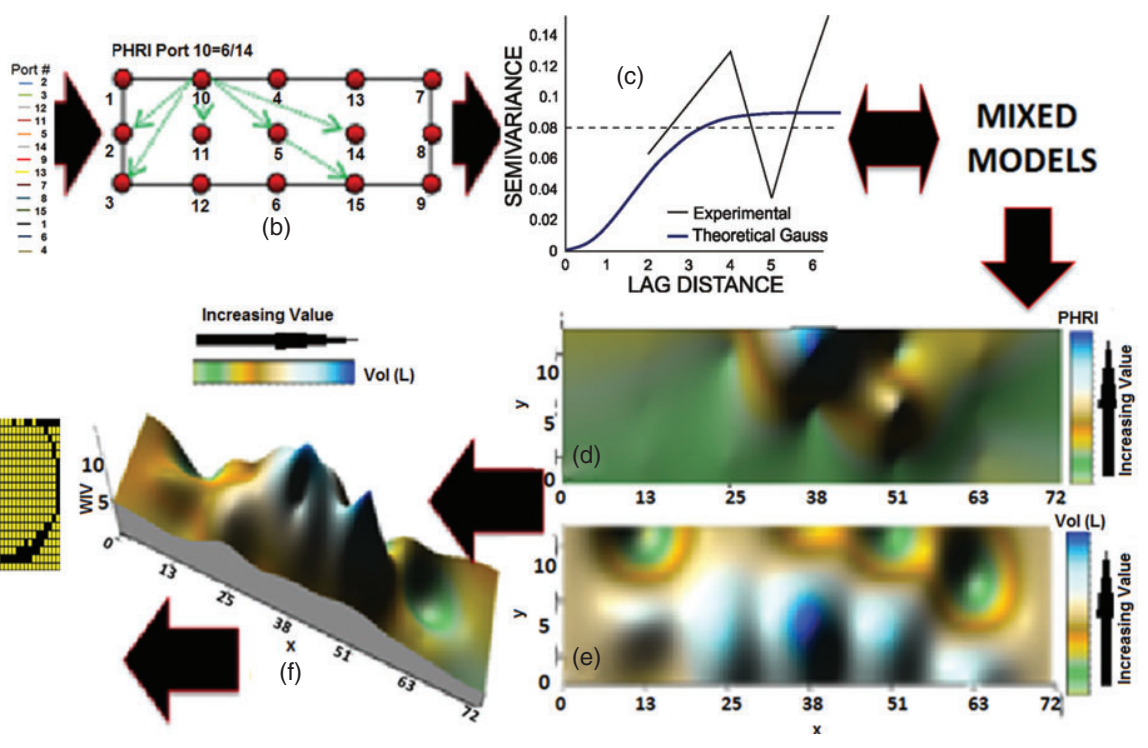

Figure 3. General method applied to characterize probable regions of preferential flow in the GHB model: (a) pressure response, (b) estimation of PHRI, (c) experimental and theoretical variograms, (d) spatial distribution of PHR and (e) injected volume, (f) weighted injected volumes, and (g) extracted preferential flow regions.

chloride concentrations using a chloride combination ion selective electrode (Accumet, Fisher Scientific). The measured data are used to generate temporal concentration distributions or breakthrough curves (BTCs) and spatial distributions of $\mathrm{Cl}^{-}$concentrations.

\section{Data Analysis}

Preferential flow paths are extracted from hydraulic response and injection volume data. The general method applied to characterize probable regions of preferential flow is summarized in Figure 3, and involves (1) estimating the Probability of Hydraulic Response Index (PHRI; defined below) for each sampler from pressure response (Figure 3a and 3b); (2) developing the experimental semivariogram of PHRI (Figure 3c); (3) applying SMMs to estimate the best SACS that represents the variability and anisotropy of the system and develop theoretical semivariograms (Figure 3c); (4) building the spatial distribution of the probability for hydraulic response (Figure $3 \mathrm{~d}$ ) and injected volumes (Figure 3e); (5) estimating the distribution of weighted injection volumes (Figure 3f); and (6) applying an analysis terrain filter to extract the preferential flow paths (Figure 3g).

The PHRI, which is estimated for each port, is the ratio of all positive pressure responses at one port (number of times that the water pressure increases at the port due the water injection in other ports) to the total number of possibilities. This ratio is independent of the magnitude of the pressure response. Since there are 15 total ports in the GHB model, but one port is being used for the injection, there are 14 total possible responses. The PHRI is used to provide information on the degree of spatial interconnection and anisotropy (level of interconnection as a function of direction) of the system.

Experimental semivariograms of PHRI data are developed using $\mathrm{SAS}^{\mathrm{TM}}$ statistical software version 9.1.2.
They describe the spatial autocorrelation of the hydraulic response at measured sample points, and reflect the statistical measure of dependency between the values. For anisotropic systems, the spatial autocorrelation is described by the variance and covariance of the data as a function of lag distance $(h)$ and separation angle $(\theta)$. In the case of the karstified limestone model, it is assumed that hydraulic response is autocorrelated for near pairs in the direction of conduit-, diffuse-, or no-flow, whichever applies. Spatial autocorrelation is related to the semivariance $(\gamma(\theta, h))$, which becomes a semivariogram when plotted as a function of $h$.

Key features of the semivariogram include the nugget effect, scale, sill, and range (Littell et al. 2006; Golden Software Inc. 2002; Sherman 2011): the nugget is the semivariance at $h=0$, and quantifies the sampling and assaying error at the short scale; the scale is the vertical component of the variogram which shows increasing semivariance with increasing lag distance; the sill is the value at which the semivariance plateaus at high $h$, and includes nugget and scale vertical components; and the range is the distance (or value of $h$ ) at which the semivariogram reaches the sill.

As the semivariance estimates are subjected to sampling error, they fluctuate from point to point, and it is best to fit a model that could describe the semivariogram continuously (Oliver 2010) and generate a continuous distribution of the spatial data. Several distance-function models can be applied to describe variograms, including spherical, exponential, linear, Gaussian, wave, quadratic, logarithmic, power, cubic, and pentaspherical (Golden Software Inc. 2002; Sherman 2011). Best-fit models are used to generate the best SACS that represents the variability and anisotropy of the system.

This work applies SMMs to the PHRI data to determine the best SACS, generate the theoretical variogram of 
the system (Figure 3c), and develop the spatial distribution of probabilistic hydraulic response from model-based predicted values in space (Figure 3d). SMMs are used because they allow us to handle uncertainty in the statistical model of spatial variability (Oliver 2010) and incorporate anisotropy variables in the optimization process.

SMMs are described by:

$$
\begin{aligned}
\mathbf{Y} & =\beta X+\mu Z+e \\
e & \sim N(0, R) \\
u & \sim N(0, G)
\end{aligned}
$$

where the vector $\mathbf{Y}$ contains observations of our target variable (PHRI), $\boldsymbol{X}$ and $\boldsymbol{Z}$ are design matrices for the fixed and random effects, respectively, the vector $\boldsymbol{\beta}$ contains the fixed-effect coefficients, the $\boldsymbol{\mu}$ vector is a spatially correlated random variable containing random effect coefficients, and $e$ incorporates errors that are independent of random errors. SMMs assume a normal distribution of the random effects, a mean of zero and a constant variance. Autocorrelation can be found in $\boldsymbol{G}$, the covariance matrix of random model effects $u$ and in $\boldsymbol{R}$, the covariance matrix of the model errors (Littell et al. 2006). This work applies the R-side approach, which adds the nugget effect to var $[e]$, resulting in covariance models with the general form:

$$
\begin{aligned}
\operatorname{Var}\left[e_{i}\right] & =\sigma^{2}+\sigma_{1}^{2} \\
\operatorname{cov}\left[e_{i}, e_{j}\right] & =\sigma^{2}\left[f\left(d_{i j}\right)\right]
\end{aligned}
$$

where $\sigma^{2}$ is the variance of measurement and model errors, $\sigma_{1}^{2}$ is the variance of the nugget effect, and $f\left(d_{i j}\right)$ is a distance function obtained from the spatial covariance and semivariance $((\gamma(\theta, h))$ models.

SMMs apply different SCAS to generate the theoretical semivariogram that best fits the experimental semivariogram data of the PHRI (Figure 3c). A total of 42 statistical models are analyzed using $\mathrm{SAS}^{\mathrm{TM}}$ statistical software version 9.1.2. The statistical models vary on the SACS (i.e., distance function model applied), nugget effect (with or without nugget effects), and the type of kriging (ordinary vs. universal) used to infer values at unobserved locations. The SACS applied include exponential, anisotropic exponential, 2D exponential geometrically anisotropic, Gaussian, 2D Gaussian geometrically anisotropic, spherical, and 2D spherical geometrically anisotropic structures (SAS Software Inc. 2008). The external drift applied for universal kriging relates to the magnitude of pressure changes in the system. Selection of the SACS is based on model similarity to experimental variance, ability of statistical lengths to represent physical dimensions, and ability of the model to meet Akaike's Information Criteria (AIC) and Bayesian Information Criteria (BIC) (Burnham and Anderson 2004). Once the best spatial structure is obtained, the theoretical semivariogram is built and incorporated in the SMM (Figure 3c) to generate the 2D spatial distribution of the probabilistic hydraulic response (PHRD; Figure 3d).

The PHRD is used in conjunction with the spatial distribution of injected volumes (IVD; Figure 3e) to generate the weighted injected volume distribution (WIVD) model (Figure $3 \mathrm{f}$ ). The IVD is generated through ordinary kriging of the experimental injected volumes, which reflect the capacity of the limestone to transmit water under given flow conditions and are influenced by pore/conduit connectivity, geometry, permeability, and characteristics of preferential flow paths. The WIVD is calculated as the spatial product of the PHRD and IVD and generated using a kriging grid of $21 \times 100$ cells $(0.76 \mathrm{~cm} \times 0.76 \mathrm{~cm}$ cells $)$. It represents a weighted fraction of the injected volume that is influenced by the probability of hydraulic response from/to other ports. Because the PHRD integrates system variability, spatial autocorrelation, and anisotropic components and the IVD integrates the spatial capacity and variability of the limestone to transmit water, it is assumed that the WIVD relates to preferential flow patterns in the limestone. Ridges of the WIVD surface response indicate a high probability of interconnected flow by a main or secondary flow network. An analysis terrain filter was applied to the WIVD using Surfer ${ }^{\circledR}$, V.8 (Golden Software) to identify the plane curvature on the WIVD map surface and extract the preferential flow paths (Figure 3g).

Spatial distribution of $\mathrm{Cl}^{-}$concentrations at given times are generated through ordinary kriging using Surfer ${ }^{\circledR}$, V.8 (Golden Software). This distribution is compared to the spatial distribution of statistically generated preferential flow regions.

\section{Results and Discussion}

The PHRI values for the different sampling ports in the GHB model show spatial variability that tends to increase in most ports as a function of background flow (Table 1). An increase in PHRI with increasing flow rates results from higher hydraulic gradients. Ports showing lower PHRI at higher flow rates suggest the influence of nearby preferential flow paths. Although injected volumes also show spatial variability, they follow similar spatial patterns for different background flows (Figure 4), varying from 2 to $12 \mathrm{~L}$ for low-flow conditions and from 2.3 to $12.5 \mathrm{~L}$ for high flow experiments. Total injected volumes, however, tend to decrease slightly (5.2\%) with increasing background flow rates due to lower pressure differentials between the injection constant head and the hydraulic pressures within the GHB model.

\section{Experimental Reproducibility}

Comparison of results from experimental replicates (Table 1) indicates that $93 \%$ of all PHRI replicates vary by one or less port-response. A port-response is defined as the probability of having a port, other than the injection port, respond to the injection from any other port in the system. For the port scheme in the GHB model, one port-response 

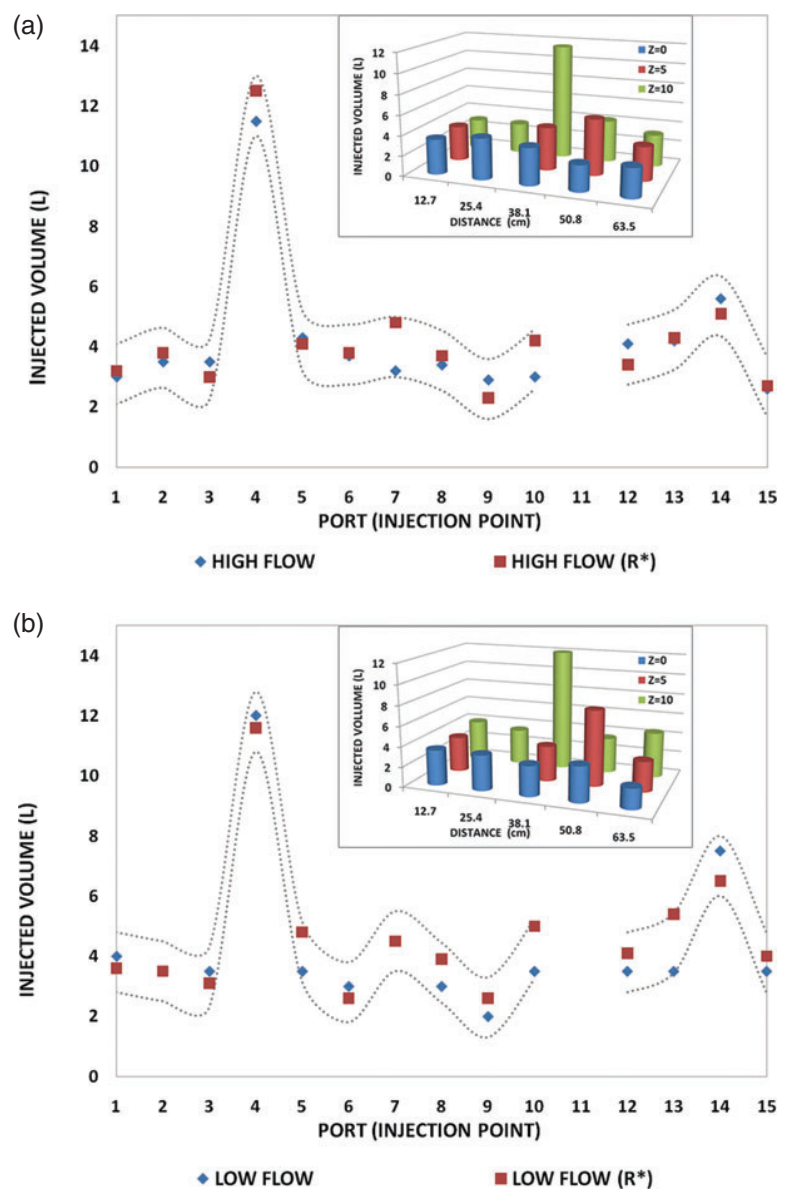

Figure 4. Injection volumes by port over a 10-minute period for (a) high- $(Q=\mathbf{7 5 0} \mathrm{mL} / \mathrm{min})$ and (b) low- $(Q=\mathbf{2 . 5}$ $\mathrm{mL} / \mathrm{min}$ ) flow. $R *$ refers to experimental replicates. Solid lines are the $\mathbf{9 5 \%}$ confidence intervals. Inset shows the spatial distribution of injected volumes.

equals $1 / 14=0.071$. Difference among replicates of one or less port-response is indicative of high reproducibility in the system. Indeed, $73 \%$ of ports in low flow conditions and $60 \%$ of those in high flow conditions have identical PHRI values, and indicate good reproducibility (Table 1). Injection volumes through the lateral ports indicate high reproducibility among experimental replicates and similar patterns for all flow conditions (Figure 4).

\section{Spatial Autocorrelation Structure}

Experimental semivariograms of the PHRI, such as the one shown in Figure 5 for a low-flow experiment, reflect the spatial variability and interconnection of the point data. Development of spatial distributions of hydraulic response, however, requires the use of a spatial function that can describe the data in a continuous space. This spatial function is integrated in the SACS and is generated by best fitting a model to the experimental semivariogram. Three SACS models best represent the experimental variance and statistical lengths of the physical system: (1) Gaussian, (2) Anisotropic exponential, and (3) Gaussian geometrically anisotropic. Ordinary kriging was the best fitting predictor in all models.
Table 2 summarizes the main statistical parameters of these models. These three models yield the closest sill $\left(\sigma^{2}\right)$ values to the experimental variance, which varies for the high (Exp. Var $=0.23)$, medium (Exp. Var $=0.35)$, and low (Exp. Var $=0.53$ ) background flows. The nugget variance in the models reflect values that are at least two orders-of-magnitude lower than the experimental variance and suggest small variance at short scales. The models reflect autocorrelation distances between 9.8 and $10.2 \mathrm{~cm}$ (autocorrelation distance $=$ product of $\rho$ and a factor of 3 for the exponential model and 1.73 for the Gaussian models; Littell et al. 2006). These distances are considered realistic realizations of the system as they all fall within the physical dimension of the GHB model.

Model results and spatial PHRI distributions generated with the best SACS models are shown in Figure 5. The correlation structures derived from the anisotropic models (Figure $5 \mathrm{~b}$ and $5 \mathrm{c}$ ) indicate a strong vertical component in the system. The highest preferential autocorrelation direction is observed in the anisotropic exponential model (Figure 5b) with an orientation angle of 89.6 degrees (given by $\arctan \left[\rho_{y} / \rho_{x}\right]$ ). This model yields a relation of 1:114 between the horizontal and vertical autocorrelated distances. In contrast, the geometrically anisotropic model yields a lower vertical autocorrelation pattern (Figure 5c) with a relation of 1:7 between the horizontal and vertical autocorrelated distances, and an orientation angle of 85.1 degrees (Table 2). The strong vertical components observed in the anisotropic models may be attributed to vertical dissolution patterns related to the genesis of the limestone block in the parental epikarst zone. The lower influence of the vertical component in the geometrically anisotropic model is representative of a system in which some horizontal dissolution patterns have developed. Visual evidence of the limestone block used in this study (Figure 1a) suggests both vertical and horizontal dissolution and flow components.

Selection of the best SACS is based on the models' fit to experimental variograms and their spatial PHRI distribution (Figure 5), autocorrelation distance, and sill variance. The anisotropic exponential model shows the lowest $R^{2}$ (Figure 5e) and extremely high vertical autocorrelation, which does not represent the physical model. This model is, therefore, rejected. The Gaussian and Gaussian geometrically anisotropic models reflect similar autocorrelation distances of about $9.7 \mathrm{~cm}$, but the Gaussian model yields a variance that is closer to the experimental variance (see Table 2) and the mean of distributed PHRI (Figure 5a) is closer to the mean of experimental PHRI (0.57 for low-flow conditions). The Gaussian model is, therefore, selected to represent the best spatial correlation structure model.

\section{Spatial Distribution Models}

The two-dimensional spatial distribution of the probabilistic hydraulic response is developed using the Gaussian autocorrelation structure model subjected to anisotropic kriging. Anisotropic kriging parameters are set as the 
Table 1

PHRI Values by Port for the Different Background Flow Conditions

\begin{tabular}{|c|c|c|c|c|c|c|c|}
\hline \multirow[b]{2}{*}{ Cluster } & \multirow[b]{2}{*}{$x(\mathrm{~cm})$} & \multirow[b]{2}{*}{$y(\mathrm{~cm})$} & \multicolumn{5}{|c|}{ PHRI by Base Flow (mL/min) } \\
\hline & & & 2.5 & $2.5 R^{*}$ & 375 & 750 & $750 R^{*}$ \\
\hline 1 & 13 & 10 & 0.077 & 0.154 & 0.692 & 0.769 & 0.769 \\
\hline 2 & 13 & 5 & 0.615 & 0.615 & 0.538 & 0.769 & 0.769 \\
\hline 3 & 13 & 0 & 0.538 & 0.538 & 0.615 & 0.769 & 0.769 \\
\hline 4 & 38 & 10 & 0.385 & 0.385 & 0.538 & 0.769 & 0.769 \\
\hline 5 & 38 & 5 & 0.923 & 0.923 & 0.692 & 0.769 & 0.846 \\
\hline 6 & 38 & 0 & 0.923 & 1.000 & 0.692 & 0.846 & 0.846 \\
\hline 7 & 64 & 10 & 0.231 & 0.231 & 0.231 & 0.154 & 0.231 \\
\hline 8 & 64 & 5 & 0.154 & 0.154 & 0.154 & 0.846 & 0.923 \\
\hline 9 & 64 & 0 & 0.692 & 0.923 & 0.923 & 0.923 & 0.846 \\
\hline 10 & 25 & 10 & 0.538 & 0.538 & 0.462 & 0.846 & 0.769 \\
\hline 11 & 25 & 5 & 0.769 & 0.769 & 0.615 & 0.846 & 0.846 \\
\hline 12 & 25 & 0 & 0.846 & 0.846 & 0.615 & 0.769 & 0.769 \\
\hline 13 & 51 & 10 & 0.154 & 0.154 & 0.385 & 0.692 & 0.846 \\
\hline 14 & 51 & 5 & 0.692 & 0.769 & 0.923 & 1.000 & 1.000 \\
\hline 15 & 51 & 0 & 0.846 & 0.846 & 1.000 & 0.923 & 0.923 \\
\hline
\end{tabular}

Notes: Horizontal $(x)$ and vertical $(y)$ distances are from the upstream and bottom faces of the limestone, respectively. $R^{*}$ refers to replicate experiments.
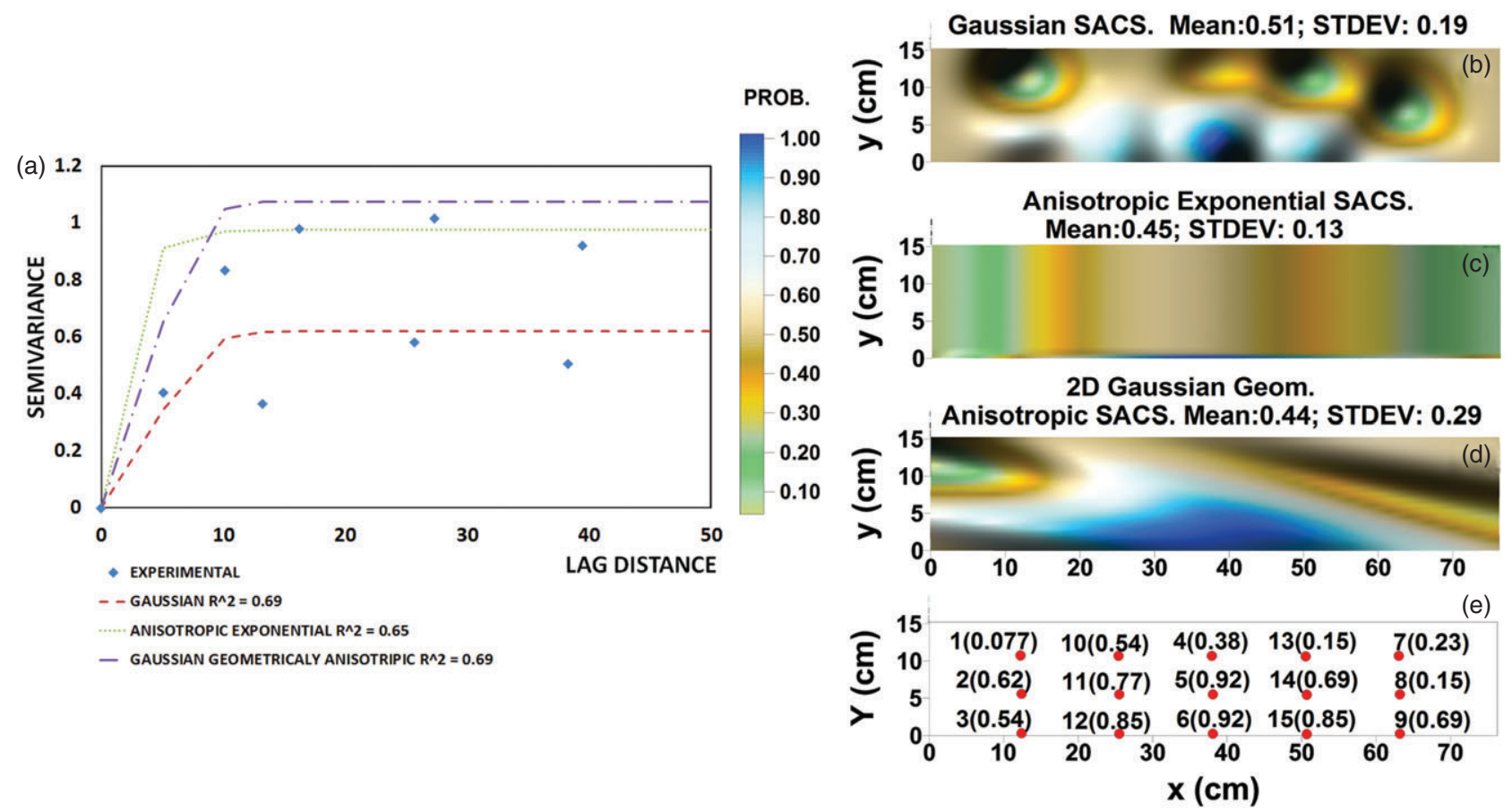

Figure 5. Spatial PRHD were generated from (a) experimental and theoretical variograms. Spatial PHRI distribution models for low-flow ( $Q=2.5 \mathrm{~mL} / \mathrm{min}$ ) experiments developed from the (b) Gaussian, (c) anisotropic exponential, and (d) geometrically anisotropic SACS are compared to the (e) experimental PHRI values shown in parenthesis next to the corresponding port number.

angle and scaling factor given by the 2D Gaussian geometrically anisotropic model $(\theta=85.1$ and $\lambda=0.15)$. Spatial distribution and average values of PHRI, IVD, and WIVD are reproducible at different background flow rates (Figure 6).

The PHRI spatial distribution and the mean of the spatially distributed values show that the probability of hydraulic response increases with increasing background flow rates (Figure 6a). These results suggest that there is greater area of hydraulic response and a greater probability of having larger preferential flow regions as flow increase. IVD distributions show slight differences in the injected volume as a function of background flow. WIVD maps have higher magnitude, but more homogeneous spatial distribution of WIVs at higher background flow conditions, especially in the lower zones of the distribution.

The preferential flow regions obtained from the statistically derived WIVDs indicate high reproducibility of 
Table 2

Summary of the Best SACS Models

\begin{tabular}{|c|c|c|c|c|}
\hline \multirow[b]{2}{*}{ Covariance Structure } & \multicolumn{4}{|c|}{ Parameters by Flow } \\
\hline & Symbol & Low & Medium & High \\
\hline \multirow[t]{3}{*}{ Gaussian model $\sigma^{2} \exp$} & Exp. Var. & 0.53 & 0.35 & 0.23 \\
\hline & $\sigma^{2}$ & 0.65 & 0.43 & 0.29 \\
\hline & $\rho$ & 5.64 & 5.64 & 5.64 \\
\hline \multirow{7}{*}{ Anisotropic exponential model $\sigma^{2} \prod_{K-1}^{c} \exp \left[-\theta_{k} d(i, j, k)^{P k}\right]$} & Exp. Var. & 0.53 & 0.35 & 0.23 \\
\hline & $\sigma^{2}$ & 0.97 & 2.51 & 0.48 \\
\hline & $\rho(x)$ & 0.03 & 0.00 & 0.08 \\
\hline & $\rho(y)$ & 3.42 & 0.02 & 0.18 \\
\hline & $P_{x}$ & 2.07 & 0.50 & 1.37 \\
\hline & $P_{y}$ & 0.00 & 2.50 & 3.51 \\
\hline & $\sigma_{1}^{2}$ & $1.0 \mathrm{E}-3$ & 0.27 & $1.9 \mathrm{E}-4$ \\
\hline \multirow{6}{*}{ 2D Gaussian geometrically anisotropic model $\sigma^{2} \exp \left[\frac{-d_{i j}(\theta, \lambda)^{2}}{\rho^{2}}\right]$} & Exp. Var. & 0.53 & 0.35 & 0.23 \\
\hline & $\sigma^{2}$ & 1.09 & 2.64 & 1.11 \\
\hline & $\rho(\theta)$ & 5.51 & 5.52 & 5.52 \\
\hline & $\lambda$ & 0.15 & 0.15 & 0.15 \\
\hline & $\theta$ & 4.87 & 4.87 & 4.87 \\
\hline & $\sigma_{1}^{2}$ & $2.5 \mathrm{E}-3$ & $1.8 \mathrm{E}-2$ & $1.2 \mathrm{E}-2$ \\
\hline
\end{tabular}

Notes: $\sigma_{1}, \sigma^{2}$, and $\rho$ correspond to the nugget, sill, and autocorrelation length (range) parameters, respectively; $d$ is distance; $c$ is the number of coordinates; $P$ is the power; and $\theta$ and $\lambda$ are the rotation angle and scaling factor $\left(=\rho_{\min } / \rho_{\max }\right)$. Values given in centimeters.
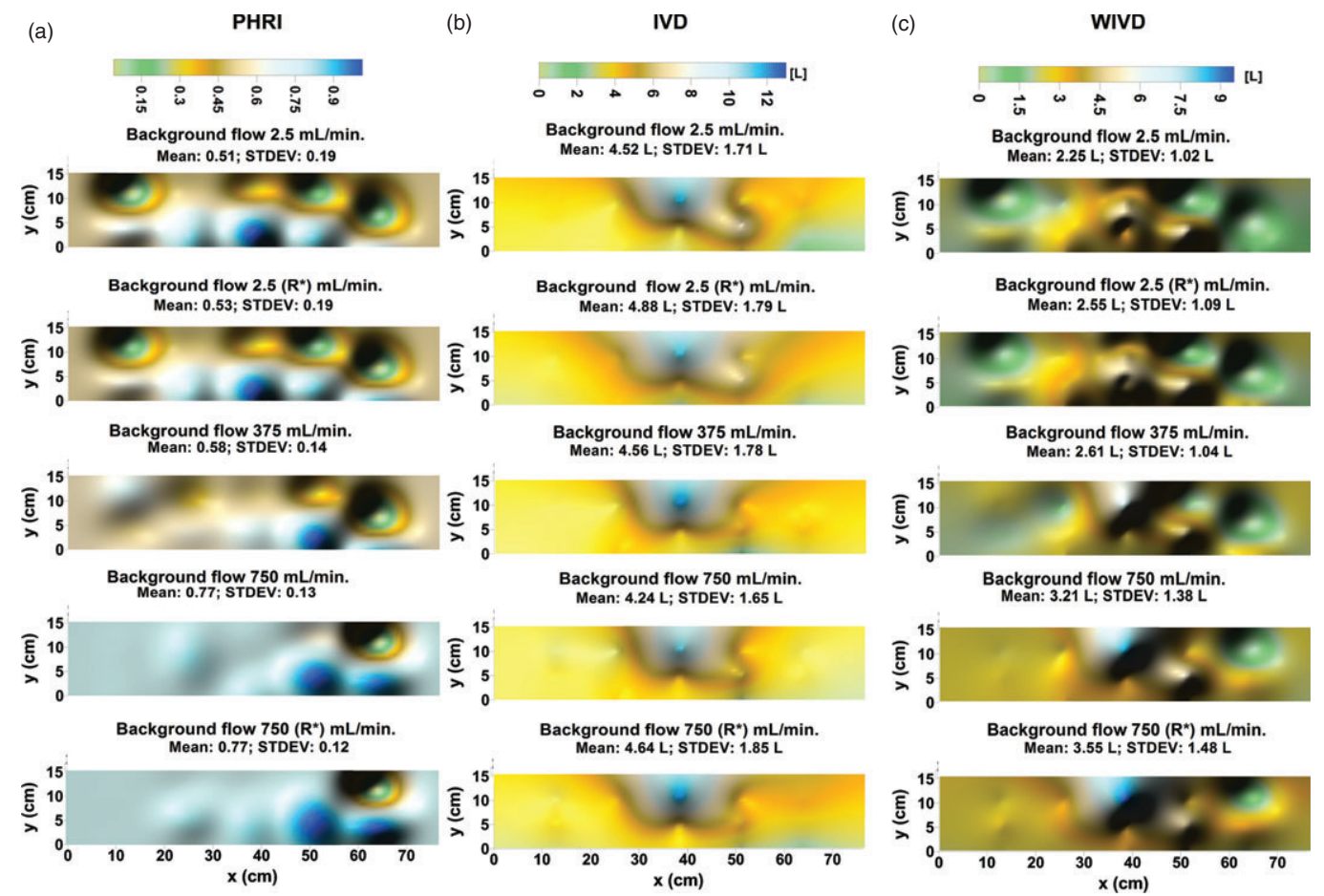

Figure 6. Spatial distribution models for different background flow: (a) PHRI model, (b) IVD model, and (c) WIVD model. $R^{*}$ refers to replicate experiments.

the results and reveal high system heterogeneity characterized by strong preferential flow components (Figure 7). Strong preferential flow and transport components in eogenetic karst systems have similarly been reported for the Biscayne aquifer in southern Florida (Renken et al.
2008; Shapiro et al. 2008). In this aquifer, rapid preferential flow occurred through touching-vug zones formed by dissolution. Statistically generated preferential flow regions (Figure 7) and the presence of structures similar to touching-vug porosity in the limestone block of the 


\section{LOW BACKGROUND FLOW 2.5 mL/min}
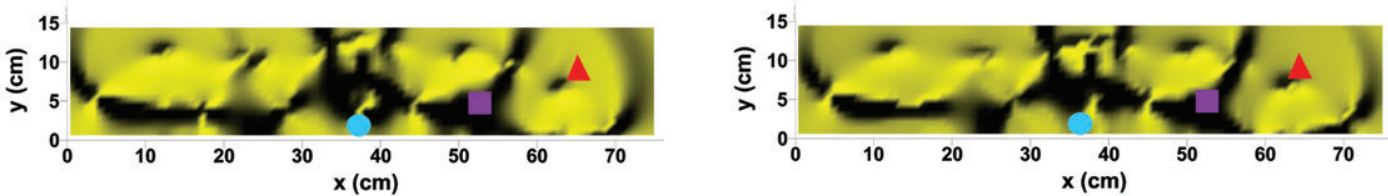

MEDIUM BACKGROUND FLOW 375 mL/min

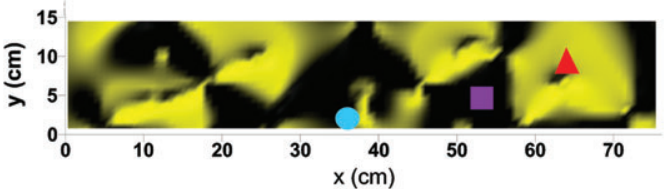

HIGH BACKGROUND FLOW $750 \mathrm{~mL} / \mathrm{min}$
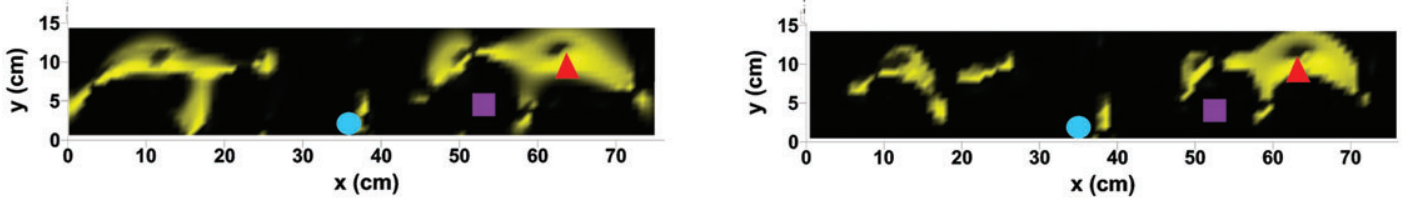

Cluster No. 6

$\triangle$ Cluster No. 7

Cluster No. 14

Figure 7. Preferential flow path regions (black areas) extracted from statistically generated WIVD distributions.

physical GHB model (Figure 1) suggest that flow in the limestone unit occurs through similar mechanisms as those in the Biscayne aquifer. Results from the statistically derived models also indicate that preferential flow regions in the GHB tend to expand from conduit-like structures into the surrounding matrix as groundwater flow increases (Figure 7). This phenomenon is attributed to the higher pressure differentials existing at higher flow. In media having considerable matrix permeability, such as those found in the karst aquifers of northern Puerto Rico, higher pressure differentials may induce higher flow in the regions surrounding the principal flow zones. Several studies documenting the exchange of water and solutes between conduits and matrix porosity in karst systems have shown that water flows from conduits into the matrix at high discharge rates (Screaton et al. 2004; Faulker 2008; Bailly-Comte et al. 2010) and moves down the regional groundwater gradients (Martin and Dean 2001). Movement of water from conduits into the surrounding matrix with subsequent flow within this matrix translates, in the physical sense, to an expansion of the flow regions. This behavior is indeed supported by the spatial preferential flow models generated from the statistical treatment of the hydraulic response in the GHB.

\section{Transport of $\mathrm{CaCl}_{2}$ Tracer}

Results from the tracer experiments show a spatially dependent response of $\mathrm{Cl}^{-}$BTCs in the GHB model (Figure 8). Spatial variations of the BTCs are explained by the location of the sampling port relative to the preferential flow regions generated with the SMMs of the hydraulic response data (Figure 7). Ports in noflow regions, such as port $\# 7$, have no response in $\mathrm{Cl}^{-}$ concentration. Ports located in regions of preferential flow, such as port \#14, have a rapid response to $\mathrm{Cl}^{-}$inputs,

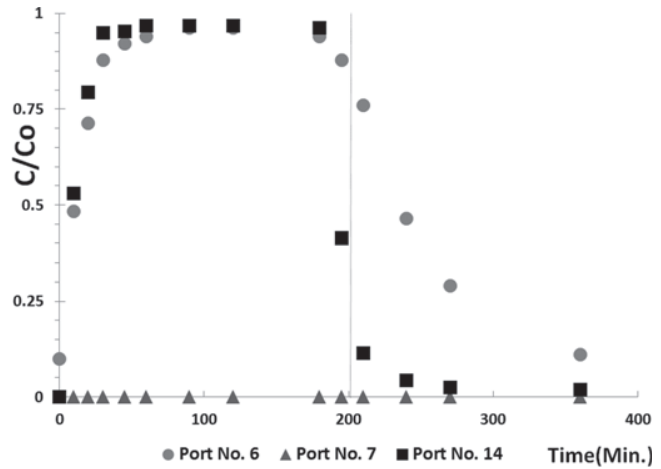

Figure 8. $\mathrm{Cl}^{-}$BTCs for ports located in conduit (\#14), diffuse, (\#6) and no-flow (\#7) flow zones for a medium flow $(375 \mathrm{~mL} / \mathrm{min})$ experiment.

with some tailing when reaching higher concentrations. Ports located in regions of diffuse flow, such as port \#6, have a rapid response to $\mathrm{Cl}^{-}$concentration changes, but present a greater degree of solute tailing near terminal input concentrations $(\mathrm{C} / \mathrm{C} 0=1$ or 0$)$, suggesting a higher mass transfer limitations. Field studies conducted in karst systems have similarly reported that dissolved solutes in conduit-dominated transport tend to have fast and relatively sharp breakthroughs, with minimal tailing (Geyer et al. 2007; Göppert and Goldscheider 2008), whereas those with significant matrix permeability show retardation and much higher degree of tailing (Renken et al. 2008; Shapiro et al. 2008).

The spatial behavior of the $\mathrm{Cl}^{-}$concentration at different times after injection (Figure 9) supports the preferential flow characterization generated from the statistically generated and filtered WIVDs (Figure 7). The spatial $\mathrm{Cl}^{-}$distribution shows that solutes follow 


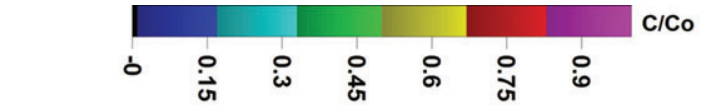

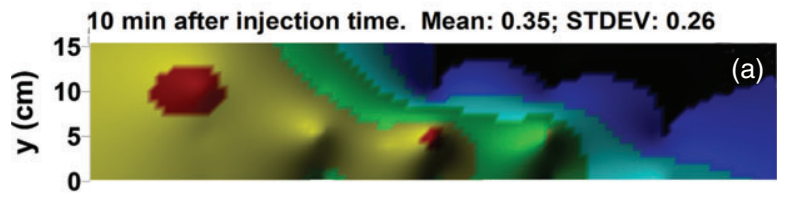

$180 \mathrm{~min}$ after injection time. Mean: $0.57 ;$ STDEV: 0.37
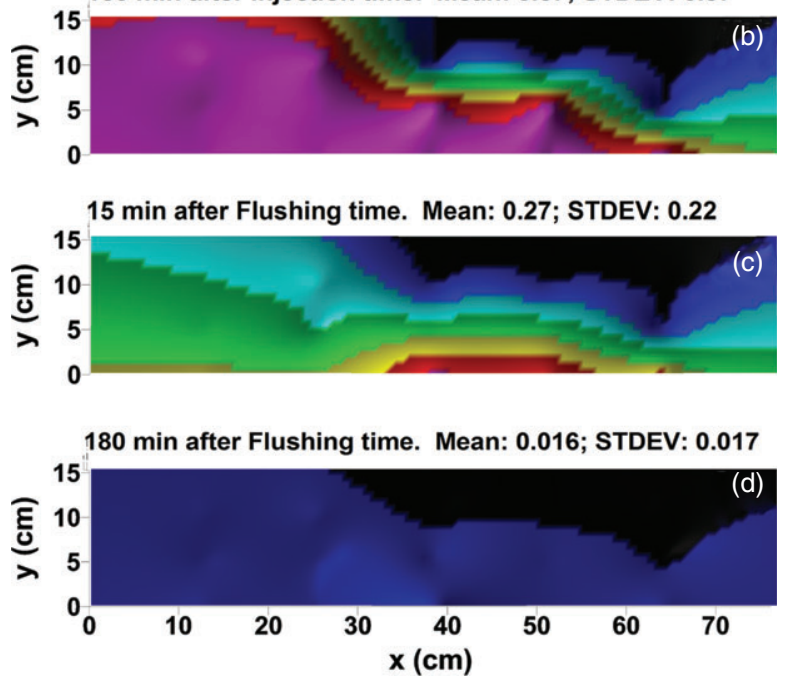

Figure 9. Spatial distribution of $\mathrm{Cl}^{-}$concentrations at: (a) 10 and (b) $180 \mathrm{~min}$ after $\mathrm{CaCl}_{2}$ injection and (c) 15 and (d) $180 \mathrm{~min}$ of flushing time for a medium flow $(Q=375 \mathrm{~mL} / \mathrm{min})$ experiment.

preferential flow paths from the early stages of the transport processes and continue to exert influence throughout the transport period. Greater spatial distribution of $\mathrm{Cl}^{-}$ at later times indicates transport from zones of preferential flow to regions of lower permeabilities influenced by diffusion flow.

Results from this work indicate that the temporal and spatial distribution of solutes in karstified limestone is influenced by the mode (i.e., conduit vs. diffuse) and spatial array of flow regions. Development and application of statistical models that can spatially characterize regions of preferential flow can, therefore, assist in the interpretation of tracer data and enhance the predictive capabilities of solute transport.

\section{Conclusions and Perspectives}

The spatial distribution of preferential flow regimes in karst aquifers results from dissolution processes over a continuous spatial scale of interconnected networks of joints, fractures, and high permeability regions. Through these processes, the rocks become highly anisotropic (Vacher and Mylroie 2002). Anisotropic flow fields in karst systems are, therefore, associated with the spatial correlation of flow parameters. This association permits the use of SACS to characterize anisotropic properties related to the flow paths in the system. SMMs provide the necessary tools to define spatial anisotropy and characterize flow features in karst systems. This work applies SMMs to spatially distributed hydraulic response data to characterize flow regions in karst systems and assess the effect of background flow rates in preferential flow patterns.

A laboratory-scale GHB model developed to simulate flow and transport processes in karstified environments shows that SMMs of hydraulic response data can be used to represent the variable transport regime characterized by combined conduit and diffuse flow in the karst systems. Hydraulic characterization indicates a highly heterogeneous system resulting in strong, flow-dependent preferential flow regions. Principal preferential flow paths seem to be influenced by structures similar to touching-vug porosity. The preferential flow regions cover smaller volumes of the system at low background flow rates, but tend to expand for higher flows. This behavior suggests that there is a greater volume of the system being flushed by flowing water at higher flow rates. Although there are no known field-scale studies documenting the expansion of preferential flow zones, several studies (Martin and Dean 2001; Screaton et al. 2004; Bailly-Comte et al. 2010) have documented strong interactions between conduits and surrounding matrix in karst aquifers having high matrix porosity. These studies show that water tends to enter the matrix region at high discharge rates, but water drains into the conduits during low flow rates. This dynamic behavior has important implications on the fate and transport of contaminants in karst aquifers with high matrix porosity. Contaminants will tend to enter regions of lower permeability during high flow seasons, where they can be sorbed and stored for long periods of time. Release of stored contaminants would thereafter occur by slow diffusion into the principal zones of flow, or by flushing the lower permeable regions during high flow conditions. This behavior could explain the long-term release of contaminants observed after removal of contamination sources in the karst aquifers of northern Puerto Rico (Padilla et al. 2011).

The presence and location of preferential and diffuse transport regions in the limestone model is supported by temporal and spatial distributions of $\mathrm{Cl}^{-}$tracer concentrations. Ports in no-flow regions show no response to chloride concentration, whereas those in regions of preferential flow show rapid response to $\mathrm{Cl}^{-}$concentrations change. Similar to karst aquifer with significant matrix permeability, ports located in regions of diffuse flow show rapid response to $\mathrm{Cl}^{-}$concentration changes, but higher degree of retention and solute tailing. The differential response of tracer concentrations at different locations in the model coincides with, and is explained by, the location of the sampling ports relative to the preferential flow regions generated with the SMMs of the hydraulic response data.

Results from this study show that the location and geometry of preferential flow regions can be deduced by applying SMMs to hydraulic information collected from laboratory-scale karst aquifers. Although the application to field-scale settings still needs to be addressed in future 
studies, it is envisioned that SMMs can be expanded to describe spatial autocorrelations of hydraulic and transport data at the field level. Scaling issues and limited observation points at the field scale are likely to pose challenges, but SMMs are adaptable and, unlike hydraulic tomography methods, can incorporate different sources of information. The models can incorporate probability of response data from injection and extraction (i.e., pumping) tests, recharge events, inputs of artificial and natural tracers, as well as data related to geologic, water flow (e.g., transmissivity), and solute transport (i.e., velocity, dispersion) parameters. Similarly to the work presented herein, spatial autocorrelations can then be applied to produce outcomes that are associated with physical characteristics of the system.

\section{Acknowledgments}

This work is supported by the U.S. Department of Energy (Grant Award No. DE-FG09-07SR22571), and the National Institute of Environmental Health Sciences (NIEHS, Grant Award No. P42ES017198). The content is the sole responsibility of the authors and does not necessarily represent the official views of the National Institute of Environmental Health Sciences or the National Institutes of Health. We express our appreciation to Dr. Ivette Cruzado for her assistance in reviewing the document and are grateful to Dr. Frank W. Schwartz and the three anonymous reviewers for their careful and detailed reviews and insightful comments, which helped to improve the final manuscript.

\section{References}

Bailly-Comte, V., J.B. Martin, H. Jourde, E.J. Screaton, S. Pistre, and A. Langston. 2010. Water exchange and pressure transfer between conduits and matrix and their influence on hydrodynamics of two karst aquifers with sinking streams. Journal of Hydrology 386, no. 1-4: 55-66.

Birk, S., R. Liedl, and M. Sauter. 2006. Karst spring responses examined by process-based modeling. Ground Water 44, no. 6: $832-836$.

Burnham, K.P., and D.R. Anderson. 2004. Multimodel inference: Understanding AIC and BIC in model selection. Sociological Methods and Research 33, no. 2: 261-304.

Clemens, T., D. Hûckinghaus, M. Sauter, R. Liedl, and G. Teutsch. 1996. A combined continuum and discrete network reactive transport model for the simulation of karst development. In Proceedings of Calibration and Reliability in Groundwater Modeling, ModelCARE 96 Conference, eds. K. Kovar and P.V. Heijde, September 1996, 309-318. Golden, Colorado: IAHS Published no. 237.

Curl, R.L. 1999. Entranceless and fractal caves revisited. In Karst Modeling, eds. A.N. Palmer, M.V. Palmer, and I.D. Sasowsky, 183-185. Charlottesville, Virginia: Karst Waters Institute Special Publication 5

Dreiss, S.J. 1989. Regional scale transport in a karst aquifer. Water Resources Research 25, no. 1: 126-134.

Einsiedl, F. 2005. Flows systems dynamics and water storage of a fissured-porous karst aquifer characterized by artificial and environmental tracers. Journal of Hydrology 312, no. 4: $312-321$

Faulker, J.A. 2008. Laboratory analog study of groundwater flow and solute transport in karst aquifers with conduit and matrix domains. M.S. thesis, The Florida State University. Electronic Theses, Treatises and Dissertations. Paper 4493. http://diginole.lib.fsu.edu/etd/4493.

Field, M.S., and P.F. Pinsky. 2000. A two-region nonequilibrium model for solute transport in solution conduits in karstic aquifers. Journal of Contaminant Hydrology 44, no. 3-4: 329-351.

Field, M.S., and S.G. Nash. 1997. Risk assessment methodology for karst aquifers: (1) Estimating karst conduit-flow parameters. Environmental Monitoring and Assessment 47, no. 1: $1-21$.

Field, M.S. 1997. Risk assessment methodology for karst aquifers: (2) Solute transport modeling. Environmental Monitoring and Assessment 47, no. 1: 23-37.

Florea, L.J., and C.M. Wicks. 2001. Solute transport through laboratory-scale karstic aquifers. Journal of Cave and Karst Studies 63, no. 2: 59-66.

Ford, D.C., and P. Williams. 2007. Karst Hydrogeology and Geomorphology, 2nd ed. Chichester, England: John Wiley \& Sons.

Geyer, T., S. Birk, T. Licha, R. Liedl, and M. Sauter. 2007. Multitracer test approach to characterize reactive transport in karst aquifers. Ground Water 45, no. 1: 36-45.

Giusti, E.V. 1978. Hydrogeology of the karst of Puerto Rico. USGS. Professional Paper 1012. Reston, Virginia: U.S. Geological Survey.

Golden Software, Inc. 2002. Surfer 8 Users' Guide. Golden, Colorado: Golden Software Inc.

Göppert, N., and N. Goldscheider. 2008. Solute and colloid transport in karst conduits under low- and high-flow conditions. Ground Water 46, no. 1: 61-68.

Green, R.T., S.L. Painter, A. Sun, and S.R.H. Worthington. 2006. Groundwater contamination in karst terranes. Water, Air, and Soil Pollution Focus 6, no. 1-2: 157-170. DOI:10.1007/s11267-005-9004-3

Hill, M.E. 2008. An evaluation of conduit conceptualizations and model performance. Ph.D. dissertation, Department of Geology, University of South Florida, Tampa.

Jaquet, O., P. Siegel, G. Klubertanz, and H. Benabderrhamane. 2004. Stochastic discrete model of karstic networks. Advances in Water Resources 27, no. 7: 751-760.

Kovacs, A., and M. Sauter. 2007. Modeling karst hydrodynamics. In Methods in Karst Hydrology, eds. N. Goldscheider and D. Drew, 201-222. London, England: Taylor and Francis.

Lapcevic, P.A., K.S. Novakowski, and E.A. Sudicky. 1999. The interpretation of a tracer experiment conducted in a single fracture under conditions of natural groundwater flow. Water Resources Research 35, no. 8: 2301-2312.

Li, G. 2004. Laboratory simulation of solute transport and retention in karst aquifer. Doctoral thesis, The Florida State University.

Littell, R.C., G.A. Milliken, W.W. Stroup, R.D. Wolfinger, and O. Schabenberger. 2006. SAS for Mixed Models, 2nd ed. Cary, North Carolina: SAS Press.

Loop, C.V.M., and W.B. White. 2001. A conceptual model for DNAPL transport in karst groundwater basins. Ground Water 39, no. 1: 119-127.

Mace, R.E., R.A. Marrett, and D.D. Hovorka. 2005. Fractal scaling of secondary porosity in karstic exposures of the Edwards Aquifer. In Sinkholes and the Engineering and Environmental Impacts of Karst, ed. B.F. Beck, 129-146. Reston, Virginia: American Society of Civil Engineers Geotechnical Special Publication 144.

Martin, J.B., and R.W. Dean. 2001. Exchange of water between conduits and matrix in the Floridan aquifer. Chemical Geology 179, no. 1-4: 145-165.

Mylroie, J.E. 2001. Karst features of Guam in terms of a general model of carbonate island karst. Journal of Cave and Karst Studies 63, no. 1: 9-22. 
Mylroie, J.R., and J.E. Mylroie. 2007. Development of carbonate island karst model. Journal of Cave and Karst Studies 69, no. 1: $59-75$.

Oliver, M.A. 2010. Geostatistical Applications for Precision Agriculture, 1st ed. Dordrecht, Netherlands: Springer. DOI:10.1007/978-90-481-9133-8

Padilla, I.Y., C. Irizarry, and K. Steele. 2011. Historical contamination of groundwater resources in the north coast karst aquifer of Puerto Rico. Dimension 25, no. 3: 7-12.

Peterson, E.E., and J.M. Ver Hoef. 2010. A mixed-model moving-average approach to geostatistical modeling in stream networks. Ecology 91, no. 3: 644-651.

Reimann, T., and M.E. Hill. 2009. MODFLOW-CFP: A new conduit flow process for MODFLOW-2005. Ground Water 43, no. 3: 321-325.

Renken, R.A., K.J. Cunningham, A.M. Shapiro, R.W. Harvey, M.R. Zygnerski, D.W. Metge, and M.A. Wacker. 2008. Pathogen and chemical transport in the karst limestone of the Biscayne aquifer: 1. Revised conceptualization of groundwater flow. Water Resources Research 44: W08429.

Renken, R.A., W.C. Ward, I.P Gill, F. Gomez-Gomez, and J. Rodriguez-Martinez. 2002. Geology and hydrogeology of the Caribbean Islands aquifer system of the commonwealth of Puerto Rico and the U.S. Virgin Islands. USGS Professional Paper 1419. Reston, Virginia: U.S. Geological Survey.

SAS Institute, Inc. 2008. SAS/STAT 9.1 User's Guide: The Mixed Procedure. Cary, North Carolina: SAS Press.

Sauter, M., T. Geyer, A. Kovacs, and G. Teutsch. 2006. Modellierung der Hydraulik von Karstgrund-25 wasserleiternEine Ubersicht. Grundwasser 3: 143-156. DOI:10.1007/ s00767-006-0140-0

Scanlon, B.R., K. Keese, and R.C. Reedy. 2003. Variations in flow and transport in thick desert vadose zones in response to paleoclimatic forcing (0-90 kyr): field measurements, modeling, and uncertainties. Water Resources Research 39, no. 7: 1179-1195. DOI:1110.1029/2002WR001604

Screaton, E., J.B. Martin, B. Ginn, and L. Smith. 2004. Conduit properties and karstification in the unconfined Floridian Aquifer. Ground Water 42, no. 3: 338-346.
Schabenberger, O., and C. Gotway. 2005. Statistical Methods for Spatial Data Analysis. Boca Raton, Florida: Chapman \& Hall/CRC.

Shapiro, A.W., R.A. Renken, R.W. Harvey, M.R. Zygnerski, and D.W. Metge. 2008. Pathogen and chemical transport in the karst limestone of the Biscayne aquifer: 2. Chemical retention from diffusion and slow advection. Water Resources Research 44: W08430.

Sherman, M. 2011. Spatial Statistical and Spatio-Temporal Data: Covariance functions and Directional Properties, 1st ed. Chichester, England: John Wiley \& Sons.

Teutsch, G., and M. Sauter. 1998. Distributed parameter modelling approaches in karst hydrological investigations. Bulletin d'Hydrogeologie: 99-110 Special issue no. 16.

Vacher, H.L., and J.E. Mylroie. 2002. Eogenetic Karst from the perspective of an equivalent porous medium. Carbonates and Evaporites 17, no. 2: 182-196.

Vesper, D.J., C.M. Loop, and W.B. White. 2001. Contaminants transport in karst aquifers. Theoretical and Applied Karstology 13-14: 101-111.

White, W.B. 2002. Karst hydrology: Recent developments and open questions. Engineering Geology 65, no. 2-3: $85-105$.

White, W.B. 1999. Groundwater flow and transport in karst. In The Handbook of Groundwater Engineering, ed. J.W. Delleur. Boca Raton, Florida: CRC Press.

Wolfe, W.J., and C.J. Haugh. 2001. Preliminary conceptual models of chlorinated-solvent accumulation in karst aquifers. In Proceedings of U.S. Geological Survey Karst Interest Group, Water-Resources Investigations. Report 014011:157-162.

Wolfe, W.J., C.J. Haugh, A. Webbers, and T.H. Diehl. 1997. Preliminary conceptual models of the occurrence, fate, and transport of chlorinated solvents in karst regions of Tennessee, USGS Water-Resources Investigations Report 97-4097, Reston, Virginia: U.S. Geological Survey.

Zack, A., T. Rodriguez-Alonso, and A. Romas-Mas. 1987. Puerto Rico Groundwater Quality. USGS, Open File Report 87-0749, Reston, Virginia: U.S. Geological Survey. 